\title{
Estado e Movimentos Sociais: Qual Autonomia? A experiência dos conselhos populares em Fortaleza
}

\author{
State and Social Movements: What Autonomy? \\ An experience of the popular councils in Fortaleza
}

\author{
Pedro Wilson da Costa Junior \\ Mestre em Sociologia (Universidade Federal do Ceará) \\ Professor da Faculdade Católica do Ceará \\ pejota9@gmail.com
}

\begin{abstract}
Resumo:
Este artigo examina alguns aspectos da relação entre Estado e movimentos sociais urbanos. O enfoque consiste na relação do Movimento dos Conselhos Populares (MCP) com a administração de Fortaleza, governada por Luizianne Lins (PT). A peculiaridade existente na relação é o fato do movimento surgido no bojo da campanha de Luizianne e que, em tese, garantiria a sustentação do "governo popular", passou a sofrer um esvaziamento por parte da administração municipal, inclusive através de práticas tradicionais na política. A experiência é emblemática por demonstrar a manifestação de sujeitos antagônicos diante das contradições econômicas materializadas na dinâmica da expansão urbana e o processo de "transformismo" nas relações sociais travadas pelo poder dominante em relação aos sujeitos antagônicos.
\end{abstract}

Palavras-chave: Movimentos sociais. Estado. Política. Classes sociais. Transformismo.

\begin{abstract}
:
This article examines some aspects of the relationship between state and urban social movements. The focus is the relationship of the Movement of People's Councils (MCP) with the administration of Fortaleza, governed by Luizianne Lins (PT). The peculiarity exists in the relationship is that the movement emerged in the wake of campaign Luizianne and that, in theory, would guarantee the support of the "popular government", has suffered a drain by the municipal administration, including through traditional practices in politics. The experience is emblematic for demonstrating the expression of subjects before the antagonistic contradictions embodied in the economic dynamics of urban expansion and the process of "transformism" in social relations waged by the dominant power in relation to the antagonistic subject.
\end{abstract}

Keywords: Social movements. State. Politic. Social classes. Transformism.

Originais recebidos em: 01/07/11

Aceito para publicação em: 12/09/11

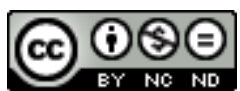

Este trabalho está licenciado sob uma Licença Creative Commons Atribuição-Uso Não-Comercial-Vedada a criação de obras derivadas 3.0 Unported License 


\section{Introdução}

Este trabalho ${ }^{1}$ examina aspectos da correlação entre Estado e movimentos sociais, por meio da experiência do Movimento dos Conselhos Populares (MCP) com a administração de Fortaleza, governada por Luizianne Lins do Partido dos Trabalhadores (PT). Destaque-se que o MCP foi criado pela ação de dirigentes petistas durante o processo eleitoral de $2004^{2}$, que elegeu Luizianne prefeita da capital cearense.

A configuração do governo Lula e os aspectos da campanha eleitoral de Luizianne evidenciavam a necessidade, para um setor da militância do PT, de ampliar o espaço de intervenção política para além do partido, não necessariamente pela formação de outra agremiação, por compreender que alguns processos internos daquele partido eram danosos para a luta política. Assim, se lançaram na tarefa de organizar uma rede de conselhos populares em Fortaleza a partir de comitês eleitorais em bairros periféricos.

As primeiras reuniões para a rearticulação do $\mathrm{MCP}$ atraíram um número significativo de participantes, que, de início, organizaram assembleias com até seiscentas pessoas em aproximadamente oitenta bairros de Fortaleza. No entanto, o movimento surgido no bojo da campanha de Luizianne e que, em tese, garantiria a sustentação do "governo popular", em pouco tempo passou a ser esvaziado pela administração municipal, via práticas tradicionais como assédio material a membros do MCP.

Tal processo exemplifica algo comum em governos que procuram se amparar, em setores organizados da sociedade civil. Não raro movimentos sociais, sobretudo suas lideranças, que estreitam o nexo com iniciativas estatais, prostram-se perante os interesses gerais da governabilidade. E a história fornece exemplos para observar que a dominação capitalista opera mutações na organização da vida estatal, para neutralizar iniciativas contra hegemônicas oriunda das classes subalternas (GRAMSCI, 2001; BRAGA, 1996).

\footnotetext{
${ }^{1}$ Extraído de um dos capítulos de minha dissertação de mestrado defendida em agosto de 2010, sob orientação da Prof ${ }^{a}$. Dr ${ }^{\mathrm{a}}$ Linda Gondim.

2 O MCP foi fundado em 2000, no entanto, apenas em 2004 passou a se organizar de modo mais permanente.

Em Debat: Rev. Dig., ISSNe 1980-3532, Florianópolis, n. 6, p. 129-152, jul-dez, 2011.
} 
Nesse sentido, investiga-se o caso de Fortaleza para ilustrar os conflitos dos governos petistas com os movimentos sociais, sobretudo a partir da ascensão do PT ao governo federal.

\section{"Novos" e "Velhos" Sujeitos}

Desde 1960, o estudo dos movimentos sociais - no bojo da ebulição política daquele período - adquiriu espaço e status de objeto científico, sendo produzidas várias teorias sobre o tema. Contudo, a guinada liberal nos países centrais e periféricos nas décadas de 1980 e 90, fez com que os paradigmas e teorias de movimentos sociais que se tornaram hegemônicos deixassem de lado as abordagens macroestruturais sobretudo as marxistas -, assim como qualquer visão próxima de um "sujeito histórico predeterminado", detentor de alguma vocação ou missão a desempenhar.

As contradições sociais passaram a ser analisadas noutros marcos e as categorias mais empregadas foram "pobres" e "excluídos" da nova estruturação do mercado de trabalho. Diante disso, conforme Gohn (2008, p. 35), “A grande tarefa política será incluí-los - tarefa que se desdobrará ao longo da década de 1990 e no novo milênio por meio de políticas sociais compensatórias ou práticas que destacam a justiça social e equidade".

No século XXI, alguns analistas consideram os movimentos sociais como "fenômenos chave" para a teoria social. Outros, todavia, consideram uma problemática já equacionada mediante a institucionalização de práticas sociais.

Para Boaventura Santos (2005, p. 174), o último período representou a ascensão de "novos protagonistas numa renovada onda de inovação e transformações sociais". Esses novos sujeitos constituíam tanto uma crítica à regulação social capitalista, como também à emancipação social socialista, enviesada pelas interpretações profundamente economicistas. Para Santos, os protagonistas destas lutas não seriam as "classes sociais", mas o que ele define vagamente de "grupos sociais", com interesses localizados, mas "potencialmente universalizáveis" (SANTOS, 2005, p. 181).

François Houtart por sua vez aloca ao proletariado a condição de "sujeito potencial" na atual dinâmica do capitalismo que, após quatro séculos de existência, conseguiu efetivamente construir as bases materiais de sua reprodução. A classe operária, segundo o autor, continuará tendo um papel importante, mas este será 
partilhado com outros atores incluindo os antigos e novos movimentos (2006, p. 423-4). Entretanto, o autor evoca uma categoria de Karl Marx - a "subsunção real do trabalho pelo capital" (MARX, 2004) - para caracterizar o processo que atinge esse sujeito potencial: "Os trabalhadores estão submetidos ao capital dentro do próprio processo de produção fazendo com que a classe operária seja totalmente absorvida e igualmente constituída pelo capital" (2006, p. 422). Esse processo ocorre em função do "novo salto" que o capital investiu nas últimas décadas. O avanço tecnológico e das comunicações elevou o poder de conglomerados econômicos dos países centrais e alterou substancialmente a correlação de forças no plano global.

Nos países centrais, a necessidade de acumulação acelerada, imposta pelos enormes investimentos em tecnologias, pelos custos de uma concentração crescente e às exigências do capital financeiro demandou uma dupla ofensiva: contra o trabalho (diminuição de empregos, salários e desregulamentação trabalhista), e contra o Estado provedor de direitos sociais (cortes orçamentários, privatizações). Tal processo debilitou consideravelmente o movimento operário: diante das periódicas crises do capital (produtivo e financeiro), inicia-se a busca de novas fronteiras de acumulação. A agricultura camponesa é progressivamente substituída pelo agronegócio, os serviços públicos essenciais passam para o setor privado, e a biodiversidade se torna base de matéria prima e de novas fontes de energia.

O resultado é que agora todos os grupos humanos sem exceção estão submetidos à lei do valor, não somente a classe operária assalariada (subsunção real), mas também os povos nativos, as mulheres, os setores informais, os pequenos camponeses, sob outros mecanismos, financeiros preço das matérias primas ou dos produtos agrícolas, serviço da dívida externa, paraísos fiscais, etc. - ou jurídicos - as normas do Fundo Monetário Internacional (FMI), do Banco Mundial (BM) e da Organização Mundial de Comércio (OMC)-, tudo isso significando uma subsunção formal (HOUTART, 2006, p. 423).

Decerto, os movimentos sociais - "novos" ou "antigos" -, são filhos de contradições que se mundializaram. Assim, as novas instituições do capitalismo globalizado exigem a ampliação do sujeito político, estendendo-se ao conjunto dos grupos sociais subalternos. "A história da humanidade caracteriza-se por uma multiplicidade de sujeitos coletivos, portadores de valores de justiça, de igualdade, de direitos e protagonistas de protestos e lutas" (HOUTART, 2006, p. 421).

É importante frisar que entre as formas de absorção desses sujeitos pelo capital está o risco de uma forçosa "institucionalização". Houtart refere-se ao medo real vivenciado pelos movimentos sociais diante dos órgãos da política tradicional. O autor

Em Debat: Rev. Dig., ISSNe 1980-3532, Florianópolis, n. 6, p. 129-152, jul-dez, 2011. 
concorda com as razões ao repúdio à "instrumentalização eleitoreira" e que a transformação social não se resume à ascensão eleitoral. Todavia, ele pondera a associação desse repúdio a uma atitude de princípio antiestatal, sobretudo entre alguns teóricos, como John Holloway (2003), e de certas ONGs (HOUTART, 2006, p. 425).

Ademais, a "subsunção" não está, necessariamente, predeterminada. Nesse sentido, Houtart (2006, p. 425) estabelece duas condições preliminares para que os movimentos sociais possam ficar em posição de construir um "novo sujeito social": 1) "ter a capacidade de uma crítica interna com o fím de institucionalizar as mudanças e assegurar uma referência permanente aos objetivos"; 2) "captar os desafios da globalização, que por sua vez são gerais e específicos ao campo de cada movimento".

Em outras palavras, devem buscar congregar os interesses de todos os que são vítimas do neoliberalismo globalizado. Além dessas exigências, concorrem outras: "movimentos sociais que se definem como a sociedade civil tem que precisar que se trata da sociedade civil de baixo, recuperando assim o conceito do Antônio Gramsci que a considera como o lugar das lutas sociais". Isso permitiria desviar das armadilhas "semânticas" elaboradas pelos grupos dominantes, como o Banco Mundial, para o qual ampliar o espaço da sociedade civil é sinônimo de restringir o lugar do Estado, "ou também na ingenuidade de muitas ONGs para as quais a sociedade civil é o conjunto de todos os que querem o bem da humanidade" (HOUTART, 2006, p. 425).

Acerca dessa "ofensiva semântica" dos poderes dominantes, cumpre salientar as reflexões de Dagnino (2004), que no contexto da hegemonia neoliberal no Brasil examina as disputas de sentido em conceitos como "cidadania", "democracia" e "participação". A autora assinala que as decorrências da implantação desse projeto sobre as sociedades latino-americanas são constatadas na reestruturação do Estado e da economia. Contudo, "os impactos desse processo sobre a cultura política de nossos países são menos reconhecidos e menos ainda em suas especificidades nacionais." (DAGNINO, 2004, p. 95).

A compreensão de tais impactos implica perceber uma "confluência perversa" entre um projeto político democratizante/participativo e o projeto neoliberal, que marcaria, hoje, o processo político brasileiro. Estaria, então, colocada uma "perversa" disputa de significados para alguns conceitos fundamentais da transição democrática, como "participação" e "cidadania": "Nessa disputa, onde os deslizamentos semânticos, os deslocamentos de sentido, são as armas principais, o terreno da prática política se 
constitui num terreno minado, onde qualquer passo em falso nos leva ao campo adversário" (DAGNINO, 2004, p. 97).

O confronto que marcou a relação entre sociedade civil e Estado nas décadas anteriores cedeu lugar, na década de 1990, a uma aposta na possibilidade de ação conjunta entre esses atores, com vistas ao aprofundamento democrático. A autora destaca que "o princípio de participação da sociedade se tornou central como característica distintiva desse projeto, subjacente ao próprio esforço de criação de espaços públicos onde o poder do Estado pudesse ser compartilhado com a sociedade" (DAGNINO, 2004, p. 97).

Entre os espaços de participação implantados nesse período, Dagnino enfatiza os Conselhos Gestores de Políticas Públicas e os Orçamentos Participativos - com destaque para a experiência pioneira de Porto Alegre, que os propagou para cerca de cem cidades brasileiras, a maioria governada pelo Partido dos Trabalhadores (PT).

Todavia, a eleição de Collor, em 1989, é um passo definidor para a aplicação dos ajustes neoliberais. É então que emerge um projeto de Estado mínimo que se isenta gradativamente de seu papel de provedor de direitos, mediante o encolhimento das responsabilidades sociais, ou pela transferência de tais para a sociedade civil.

No caso brasileiro o projeto neoliberal teve que se defrontar com um projeto político democratizante - não hegemônico -, tecido na resistência ao regime autoritário e exigente da ampliação da cidadania e da participação da sociedade civil. A existência desse projeto/campo democratizante determinaria outras estratégias e formas de atuação das forças neoliberais.

Assim, a interlocução entre o projeto neoliberal, que ocupava majoritariamente o Estado, com o projeto participativo, se dá, em grande medida, via setores da sociedade civil que passam a atuar nas novas instâncias de participação junto ao Estado. Diante dessa "interlocução" ocorre uma tentativa - em parte, exitosa - de "re-significar" algumas noções que constituíam o núcleo central do projeto participativo: “O princípio básico aqui parece ser a adoção de uma perspectiva privatista e individualista, capaz de substituir e redefinir o significado coletivo da participação social.” (Ibidem, p. 102).

Muitos dos espaços abertos à "participação" da sociedade civil na formulação de políticas públicas constituem, de fato, substitutos do Estado na execução de determinados serviços. Contudo, o poder real de decisão na formulação dessas políticas públicas fica reservado ao "núcleo estratégico" dos governos. Nisto consiste o caráter 
das denominadas "organizações sociais" designadas pela Reforma Administrativa do Estado - conduzida pelo ministro Bresser Pereira, em 1995, durante o primeiro governo FHC - como forma de participação da sociedade civil nas políticas públicas.

Seguindo a "despolitização da participação", o conceito de sociedade civil passa a ser cada vez mais confundido com o de mercado. Daí, explica-se a substituição do seu significado político em tratar temas como desigualdade social e pobreza via soluções individualizantes, como a ênfase no trabalho voluntário mediante a "participação solidária" e a "responsabilidade social" - de indivíduos e empresas. "A própria ideia de 'solidariedade', a grande 'bandeira' dessa participação redefinida, é despida de seu significado político e coletivo, passando a apoiar-se no terreno privado da moral" (DAGNINO, 2004, p. 102). A noção de cidadania é, talvez, o exemplo mais dramático de deslocamento de significado: Tornar-se cidadão passa a significar a integração individual ao mercado, como consumidor e como produtor.

Esse parece ser o princípio subjacente a um enorme número de programas para ajudar as pessoas a "adquirir cidadania", [...] Num contexto onde o Estado se isenta progressivamente de seu papel de garantidor de direitos, o mercado é oferecido como uma instância substituta para a cidadania (ibidem, p. 106).

A assimilação dessas re-significações pelo "projeto participativo", conforme Dagnino (2004), reflete em boa medida o impacto ideológico do neoliberalismo no Brasil sobre diferentes segmentos, com destaque para os estratos mais pauperizados da sociedade civil. Vale destacar que, com a hegemonia petista em âmbito federal, ocorre também uma sensível moderação de boa parte dos movimentos sociais (Cf. OLIVEIRA (2006), BOITO (2006), DEMIER (2003), FILGUEIRAS, L.; GONÇALVES, R., (2007)).

Mirza (2006) destaca a questão da autonomia dos movimentos sociais em relação às estruturas de poder. Para ele, existe um vínculo histórico entre os movimentos sociais e os sistemas políticos, herdado do século XX, que tem impedido o fortalecimento dos movimentos. Para Mirza, movimentos com autonomia débil ou ausente se tornam incapazes de ativar processos democráticos enraizados na sociedade civil, além de comprometerem sua própria legitimidade e credibilidade social.

Segundo Touraine

a subordinação dos movimentos sociais à ação do Estado constitui a limitação mais grave de sua capacidade de ação coletiva autônoma. [...] é preciso inverter a relação e reconhecer que os movimentos sociais só se constituem e se integram entre si na medida em que estão em relação com 
forças políticas que não são de modo algum seus representantes, mas que apoiam sobre eles sua estratégia. (TOURAINE, 1989, p. 182, 17).

De outro modo Thwaites Rey afirma que, em certas perspectivas, "radicalizar la democracia se emparenta con una suerte de construcción de mitos en torno a la participación autónoma, autogestiva u horizontal." (REY, 2004, p. 47). A autora denomina este aspecto de "autonomia mitificada".

\section{Revolução Passiva, Contra Reforma e Transformismo}

Segundo Braga (1996, p. 170), o conceito gramsciano de "revolução passiva" assume, no bojo da crise capitalista contemporânea e da reestruturação produtiva em curso, uma dimensão agudamente central diante do "reformismo socialdemocrata" que tenta impedir a realização do "potencial ético-político" daquelas classes.

Coutinho (2007) questiona se a época neoliberal aproxima-se mais de uma revolução passiva ou de uma contra reforma. Em sua análise estabelece uma distinção entre neoliberais "doutrinários duros e puros" e os defensores de uma pretensa "terceira via", dizendo que os primeiros tinham pelo menos o mérito da sinceridade ao se denominarem "conservadores". Já os últimos, que se apresentam como representantes de uma posição ligada às exigências da modernidade e do progresso, na realidade constituíam uma versão atualizada da ideologia neoliberal. Em tal contexto, a resposta para a questão levantada por Coutinho é condicional.

A utilização da ideia de revolução passiva esbarra no descompasso entre conceito e prática, pois esta noção se aplica às "reformas pelo alto", quando são feitas transformações na estrutura social e política, sem necessariamente contar com a participação das "classes subalternas". Aqui, ele acredita que a noção de contra reforma (conceito pouco empregado por Gramsci nos Cadernos) se aplica melhor, no sentido de uma restauração levada a cabo pelos neoliberais ao destruírem determinadas conquistas do período do Welfare State.

Outro conceito que contribui para a compreensão do período atual é o de transformismo. Gramsci lança mão da categoria ao analisar o Partido da Ação, que se submeteu à "direção intelectual e moral" de seu opositor, os Moderados, durante o Risorgimento - mobilizações nacionais que culminaram na unificação e fundação do Estado italiano moderno, na segunda metade do século XIX -, que consistiu em uma "revolução sem revolução" ou revolução passiva. 
Transformismo consiste na cooptação ou assimilação de indivíduos - adjetivado como molecular - , ou de setores das classes subalternas a um consenso conferido pelo bloco dominante. Segundo Gramsci,

\begin{abstract}
não existe uma classe independente de intelectuais, mas cada grupo social tem um próprio grupo de intelectuais ou tende a formá-lo para si; porém, os intelectuais da classe historicamente (e realisticamente) progressiva, nas dadas condições, exercem um tal poder de atração que acabam, em última análise, por subordinar a si os intelectuais dos outros grupos sociais e, portanto, por criar um sistema de solidariedade entre todos os intelectuais com ligações, de ordem psicológica (vaidade, etc.) (GRAMSCI, 1978, p. 277).
\end{abstract}

Desse modo, as classes dominantes italianas, via Risorgimento, realizaram uma revolução passiva, pelo alto, sem a participação das massas: "a tática transformista do grupo moderado opera uma radicalização dosificada e um empobrecimento do aspecto da radicalidade dos subalternos" (BRAGA, 1996, p. 172, grifo original). O desfecho principal do transformismo, segundo Gramsci, é a "decapitação" dos grupos progressistas e seu aniquilamento por um longo período. De acordo com Braga

O transformismo é o modo próprio de ação política de um "tornar-se" Estado
para o caso de uma classe debilitada e que, necessariamente, deve excluir a
ação das massas, aliando-se às velhas classes para chegar ao poder e manter-
se nele. [...] Em síntese, o transformismo pode ser traduzido pela
materialização de um projeto de formação do moderno Estado burguês
através da assimilação do opositor (antítese) em uma única tendência
moderada do aparato de governo (BRAGA, 1996, p. 172).

Coutinho (2007) ressalta que o transformismo não é um fenômeno político exclusivo dos processos de revolução passiva, pois ele pode também estar ligado a processos de contra reforma, exemplificada na "ação de socialdemocratas e de excomunistas no apoio a muitos governos contra reformistas em países europeus, mas também fenômenos como os governos Cardoso e Lula num país da periferia capitalista como o Brasil."

Uma característica desta segunda posição é a utilização, distorcida, da ideia de "reforma". Essa palavra, que sempre fora vinculada às lutas dos subalternos para transformar a sociedade, assumindo uma conotação progressista e de esquerda, pois significava ampliação de direitos, proteção social, controle do mercado, etc., no contexto neoliberal, passou a significar cortes, supressão de direitos, liberdade de mercado. "Estamos diante de uma operação de mistificação ideológica que, infelizmente, tem sido em grande medida bem sucedida" (COUTINHO, 2007). 


\section{O Movimento dos Conselhos Populares}

O MCP foi fundado por militantes petistas durante as eleições municipais de 2000. O objetivo do movimento era dar consistência política aos comitês eleitorais do candidato da coligação de esquerda, Inácio Arruda, do PC do B, no período posterior à campanha. No entanto, a proposta não logrou êxito. Por isso, a reorganização do movimento só ocorreu em 2004, durante a eleição de Luizianne Lins (PT) para a prefeitura de Fortaleza.

Luizianne Lins assumiu a proposta dos Conselhos Populares já no início da disputa eleitoral, defendendo-os em comícios e na mídia. A proposta constituía um dos eixos principais do programa de participação popular do governo, registrando-se o compromisso de prezar pela relação autônoma entre Estado e conselhos. Além disso, alicerçaria o Orçamento Participativo (PROGRAMA DE GOVERNO, 2006 [2004]).

Realmente, a massificação da campanha eleitoral petista pelos bairros periféricos de Fortaleza permitia idealizar os tais conselhos na cidade. Dessa forma, parte da coordenação de campanha de Luizianne passou a fomentar um movimento popular como saldo organizativo daquele processo eleitoral - do qual, poucos esperavam uma vitória nas urnas, vale registrar. Ademais, a necessidade de um movimento com esse perfil popular refletia, em boa medida, as angústias e frustrações que muitos militantes sentiam em relação ao PT, sobretudo, após a vitória de Lula. Afinal, todo esse processo esteve inserido na disputa interna que existia no partido e no governo federal.

A primeira reunião do $\mathrm{MCP}$, ainda durante o segundo turno das eleições, agregou mais de 500 pessoas de diferentes bairros da capital cearense. O movimento, entre novembro de 2004 e fevereiro de 2005, realizou cerca de 80 assembleias nos bairros, onde, na maioria dos casos, foram organizados comitês populares durante a campanha. Todas as assembleias contavam com mais de uma centena de participantes,

algumas com quinhentas ou seiscentas pessoas. ${ }^{3}$ A identificação do governo eleito com as demandas populares explicava essa participação. As assembleias discutiam a cartilha com os princípios do MCP e elegiam as principais demandas de cada local. Para a coordenação do movimento, as assembleias foram centrais para robustecer de forma orgânica a construção do MCP.

\footnotetext{
${ }^{3}$ Dados coletados presencialmente e confirmados em entrevistas.

Em Debat: Rev. Dig., ISSNe 1980-3532, Florianópolis, n. 6, p. 129-152, jul-dez, 2011.
} 
Inicialmente debateu-se qual relação o movimento teria com a nova gestão municipal. A ideia era que as iniciativas populares da administração gerariam enfrentamentos com grupos dominantes na cidade, demandando sustentabilidade social para a gestão, a ser encontrada nos conselhos populares de cada bairro. Na cartilha "Princípios do MCP”, foram postuladas tarefas aos conselhos populares contribuírem, de forma independente, com a governabilidade da gestão, sobrepondo-se ao jogo político tradicional.

Esse raciocínio, contudo, não dava conta da problemática. Era necessário elaborar definições menos tênues sob o risco de colocar em jogo a sobrevivência do MCP, em função do descompasso entre o discurso de independência ao governo municipal e um sentimento difuso entre alguns militantes de que "esse movimento vai ser um grande auxílio para essa administração.” (INFORMATIVO..., 2005).

A relação intrínseca com o grupo político que estava à frente do Executivo Municipal levou muitos a crer que o MCP seria um "braço social" do governo, visão rechaçada por seus coordenadores. Segundo depoimento, "a coisa que mais era debatida no início do movimento era a questão da independência em relação ao governo" (Informante 1).

Já na Assembleia da Cidade $^{4}$, contradições ficaram evidentes entre governo e movimento. A presença de vereadores da antiga base aliada do prefeito Juraci Magalhães, agora integrantes da base de Luizianne, gerou mal-estar entre alguns participantes, que chegaram a vaiá-los. Apesar do constrangimento, a assembleia cumpriu o seu papel ao apresentar o programa de reivindicações e ao conferir maior visibilidade política ao MCP.

Entretanto, a "distância entre intenção e gesto" da prefeitura ficou evidente na lentidão no encaminhamento das reivindicações e, sobretudo, na oposição entre o movimento e alguns secretários e gestores. De acordo com os coordenadores do movimento, a razão desse conflito era a distribuição de cargos nas secretarias do governo. Alguns políticos "inimigos" do movimento ocuparam a direção dos órgãos responsáveis pelo encaminhamento das reivindicações do MCP.

\footnotetext{
${ }^{4}$ Ato ocorrido em 09/04/2005 com mais de dois mil participantes, que foi considerado pelos coordenadores do movimento como marco fundante do MCP. Naquele ato, foi entregue à prefeita e ao então presidente da Câmara dos Vereadores de Fortaleza, Tin Gomes (PHS), o "Programa de Reivindicações Imediatas do Povo de Fortaleza". O documento reunia as principais demandas recolhidas nas assembleias dos bairros e constavam quatro pontos: Tarifa zero nos transportes coletivos de Fortaleza; Frentes de Serviços nos bairros; Socialização do Trabalho Doméstico; Grande Biblioteca Pública da Cidade.
}

Em Debat: Rev. Dig., ISSNe 1980-3532, Florianópolis, n. 6, p. 129-152, jul-dez, 2011. 
Sob o argumento da responsabilidade por uma grande capital brasileira, com enormes problemas e carência de recursos, Luizianne tratou de "viabilizar" sua gestão. Ela que sofrera oposição da direção do seu partido e do governo federal, que no primeiro turno apoiaram abertamente o candidato do PCdoB, Inácio Arruda, logo se reconciliou com a cúpula partidária e do governo.

Aqui, vale recordar a afirmação à imprensa, durante o segundo turno das eleições municipais de 2004, do então ministro da Educação e dirigente petista, Tarso Genro: "Prefeitos adoram ser governistas." Na mesma entrevista, sobre a possibilidade da candidata Luizianne se filiar ao PSOL, caso eleita prefeita de Fortaleza, o ministro afirmou: "Acho que ela continuará no PT se for eleita. Para um prefeito de capital, é muito importante ser do partido do presidente da República." (Revista Isto É, 20/10/2004).

Concomitante à reaproximação com a direção nacional do PT, a prefeita de Fortaleza passou também a reproduzir o mesmo tipo de governabilidade conduzida em nível federal. Antes mesmo de tomar posse, articulou-se uma coalizão, na qual a nova gestão, que contava com apenas quatro vereadores dos 41 eleitos, conseguiu maioria parlamentar. $^{5}$

Nos escalões inferiores da gestão ocorreu a distribuição de cargos aos novos aliados, bem como foram mantidas, em vários cargos comissionados, pessoas vinculadas à gestão anterior. "a gente viu que não só os vereadores do bairro não perderam o poder, como aumentaram o poder. Na nossa região, o cara 'controlava' uma escola e passou a 'controlar' duas, três escolas" (Informante 3$)^{6}$.

A relação $\mathrm{MCP} /$ governo também desembocou em uma complexa rede de relações e interesses. Por vezes, o movimento era assediado por grupos ou indivíduos interessados em cargos ou maiores atribuições no governo, pois a visão difundida era que o MCP possuía forte representação política para a prefeita, chegando a influir sobre políticas e cargos. "O nosso primeiro sucesso foi impedir que o MCP virasse o lugar dos insatisfeitos por espaço na gestão [...] tinha muita gente que vinha pro movimento criticando a prefeitura, aí conseguia um emprego lá e saía [do movimento]” (Informante 2).

\footnotetext{
${ }^{5}$ Dos quatro vereadores eleitos na coligação PT-PSB, Guilherme Sampaio (PT), José Maria Pontes (PT), Salmito Filho (PT) e Sérgio Novaes (PSB), apenas o último apoiou Luizianne desde o primeiro turno. Uma aliança entre vários partidos com o apoio da prefeita elegeu Tin Gomes, do PHS, para a presidência da Câmara dos Vereadores. Vale registrar que Tin Gomes havia sido assessor direto de Juraci Magalhães. ${ }^{6}$ Refere-se à indicação por parte de vereadores de diretores e outros cargos para as escolas do município.

Em Debat: Rev. Dig., ISSNe 1980-3532, Florianópolis, n. 6, p. 129-152, jul-dez, 2011.
} 
No geral, essa foi maior adversidade para o MCP, logo em seu início. "algumas pessoas assumiram seus cargos e outras perceberam que lá [no $\mathrm{MCP}$ ] não era o lugar para se ganhar cargos, foram tentar via os partidos. Aí começou uma diminuição no movimento" (Informante 1).

Vale ressaltar que tal movimento rumo à prefeitura atingiu vários militantes que, guardadas as devidas diferenças, estavam comprometidos desde o início com a organização do MCP. Dessa forma, o movimento diminuiu sensivelmente seu poder de mobilização e os conflitos com a gestão tornaram-se mais agudos.

Tornava-se cada vez mais evidente que as escolhas políticas tomadas por Luizianne caminhavam em sentido oposto ao esperado. Um dos dirigentes do MCP, à época, afirma que o fato de o movimento ter mantido firmemente a defesa de sua autonomia - em sua visão o que tornou possível a sobrevivência do movimento - em relação às políticas da prefeitura, gerou como reação uma forte hostilidade da gestão ao movimento em seus locais de atuação, através do não cumprimento de acordos, manipulação de informações e cooptação ${ }^{7}$.

Diante dessas atitudes da prefeitura, o MCP necessitava responder às demandas da sua base organizada, sob pena de se esvaziar politicamente. Tal questão maturou o afastamento de militantes que ocupavam cargos na gestão e, mais à frente, na retirada do MCP de alguns espaços de participação popular, especialmente do Orçamento Participativo, durante o terceiro ano do programa (2007).

O processo de "sangria" do movimento foi contínuo durante o período inicial da gestão de Luizianne. De fato, a situação era difícil de resolver, pois a maioria dos membros do MCP pertencia aos segmentos de baixa renda, cujas necessidades materiais poderiam ser minimizadas via ingresso na administração ou apoio a ela. Era a oportunidade de um emprego com relativa estabilidade e com remuneração acima das possibilidades existentes no mercado de trabalho para pessoas com baixa escolaridade e pouca qualificação profissional. $\mathrm{O} \mathrm{MCP}$ teve que buscar em si a resposta para a fragilidade organizativa advinda da saída de seus principais militantes, sobretudo os mais experientes. O movimento precisou formar os seus próprios "intelectuais orgânicos":

Boa parte dos seus dirigentes iniciais sai do movimento e vão pra prefeitura. Então aquela turma mais jovem e bem menos experiente no movimento popular, que estava no movimento estudantil, acaba assumindo o movimento

\footnotetext{
${ }^{7}$ Práticas relatadas em todas as entrevistas com diferentes exemplos.

Em Debat: Rev. Dig., ISSNe 1980-3532, Florianópolis, n. 6, p. 129-152, jul-dez, 2011.
} 
e daí pra frente "toca" as lutas e as reivindicações que vem da comunidade, organizam núcleos de militantes nas comunidades (Informante 4).

A renovação da coordenação do movimento apressou o distanciamento com a gestão municipal. Mesmo que muitos membros do MCP fossem também vinculados ao PT, seu pulsar militante era mais ávido em relação àqueles mais calejados, que eram continuamente adestrados pela atuação nas engrenagens do Estado. Ademais, os militantes mais jovens eram menos apegados em relação ao simbolismo (e à estrutura) do PT, considerando que atuavam em um momento em que o partido marchava progressivamente para a moderação, distante daquele velho PT saudado pelos antigos.

O ano de 2005 correspondeu ao primeiro ano de governo Luizianne e de existência efetiva do MCP. A confusa relação entre as duas esferas políticas perdurou naquele período. O movimento se voltou principalmente para sua constituição, com reuniões em bairros, formações políticas. O momento exigia trabalho para consolidar sua base social, bem como reflexão, pois a inesperada "guinada" do governo demandava novas formulações e planos de ação para garantir as reivindicações acordadas na Assembleia da Cidade. Aliás, esse foi um ano de perplexidade e de redefinições para toda a esquerda brasileira ${ }^{8}$.

Entre o final de 2005 e o início de 2006, ganha maturidade no interior do MCP o debate acerca do papel que poderia desempenhar no cenário de lutas sociais de Fortaleza. As circunstâncias desfavoráveis que marcaram aquela etapa incipiente do movimento, as contradições com a gestão petista, o afastamento de militantes e a própria reorganização da esquerda brasileira, começava a ficar mais discernível para o conjunto do MCP.

foi uma reflexão interna nossa. Nós começamos a pensar o seguinte: Por que não existem conselhos? Por que o MCP, que era pra ser "o movimento" da cidade, virou mais um movimento em Fortaleza? Cadê aquelas dezenas, centenas de militantes que acreditavam? Cadê o povo participando? Aí nós fomos entender a nossa história (Informante 3).

De fato, além das condições desfavoráveis já descritas, o MCP estava longe de ser espaço de convergência dos movimentos populares da capital cearense, pois era encarado com desconfiança pelas organizações populares, desde as que se situavam, de algum modo, dentro no campo da prefeitura, como a CMP e a FBFF, até aquelas mais à esquerda, como o Movimento Luta nos Bairros (MLB) e o PSTU.

\footnotetext{
${ }^{8}$ Ano do episódio do "mensalão" que atingiu parlamentares e dirigentes do PT, abalando a estabilidade do governo. Muitos militantes e personalidades acadêmicas se afastaram do partido. Neste mesmo ano duas organizações surgidas na esteira do PT se lançam: o PSOL obtém o registro eleitoral e o Movimento Consulta Popular se restabelece como organização política.

Em Debat: Rev. Dig., ISSNe 1980-3532, Florianópolis, n. 6, p. 129-152, jul-dez, 2011.
} 
A realidade mostrava a impossibilidade de um "governo dos conselhos populares", até pela complexidade de mobilizar segmentos populares para uma causa pouco palpável, sobretudo em período de refluxo das lutas sociais. Além disso, as demandas mais concretas e urgentes desses segmentos se impunham como dado de realidade, e forçavam o $\mathrm{MCP}$ a refletir sobre suas estratégias. Essa compreensão desencadeou um salto organizativo considerável para o movimento, que elege algumas prioridades de atuação para permanecer em interlocução com os segmentos mobilizados durante as primeiras assembleias nos bairros.

De início, a primeira luta massiva do MCP foi a "Campanha Contra o Desemprego", por meio da organização de núcleos de desempregados de Fortaleza para as "Frentes de Trabalho". O processo permitiu ao MCP restabelecer um patamar organizativo, "porque houve uma conjuntura favorável a construir o $\mathrm{MCP}$, mas essa conjuntura não existia mais em 2006, e através da luta [por trabalho] nós estávamos em 30 bairros de novo, uns com mais consistência, outros menos."

As primeiras manifestações do MCP deram consistência organizativa e solidariedade militante entre os participantes. Este, na visão da coordenação do movimento, teria sido o principal saldo político da luta pelas Frentes de Trabalho: "Politicamente, as Frentes de Trabalho tinham sido importantes porque tinham dado um gás pro movimento. A gente fez manifestações com 500 pessoas, 400 pessoas" (Informante 1).

Inicialmente, o movimento necessitou convencer o governo da justeza da proposta e de sua exequibilidade, para tanto elaborou, inclusive, uma cartilha sobre essa luta, na qual se explicam os propósitos das "Frentes":

\begin{abstract}
a abertura dessas Frentes de Serviços Urbanos destina-se a treinar e contratar, em cada bairro das periferias da cidade, homens e mulheres desempregados, principalmente estas últimas, para a realização de algumas atividades de interesse coletivo, tais como vigilância, limpeza e conservação de ruas, praças, monumentos e outros equipamentos de uso comum do povo, como prédios comunitários e públicos, em particular escolas, postos médicos, bem como a despoluição de rios, riachos e lagoas, plantio de árvores, jardinagem pública, construção de casas populares etc. A ideia fundamental é que os desempregados possam intervir para melhorar a infraestrutura urbana e social da cidade e receber uma contrapartida financeira. (MOVIMENTO..., s/d. (Cartilha).
\end{abstract}

A proposta, de início, previa um total de 20 mil beneficiados, número que caiu para 10 mil durante as primeiras negociações com a Administração Municipal. No entanto, a Secretaria de Desenvolvimento Econômico (SDE) do município, alegando restrições orçamentárias, assegurou apenas 4 mil vagas.

Em Debat: Rev. Dig., ISSNe 1980-3532, Florianópolis, n. 6, p. 129-152, jul-dez, 2011. 
O projeto "Com os Pés no Chão: Frentes de Trabalho Urbanas para Fortaleza" atenderia, no geral, chefes de famílias que estivessem desempregados ou desocupados, residissem em Fortaleza há, no mínimo, dois anos e não fossem contemplados em programas de renda mínima. A jornada de trabalho seria de 30 horas semanais, sendo de 20 a 24 horas para as atividades laborais e de 06 a 10 horas para atividades socioeducativas e de participação política. Cada trabalhador seria contratado por três meses, evitando formar vínculo empregatício. Por fim, a Prefeitura e a SDE se comprometiam a procurar parcerias com outras instituições para suprir a demanda.

Apesar da redução do número de beneficiados, o MCP, com ressalvas, aceitou a contraproposta. Posteriormente, esbarrou-se na morosidade de trâmites burocráticos da administração e na inconstância do governo diante dos valores acordados: "A gente passou 2007 envolvido nessa luta, só que o governo não se mexia, era muito burocrático. [...] e o problema de se reunir e prometer uma coisa $\mathrm{x}$, e um mês depois dizer que era $80 \%, 50 \%$, e o movimento tendo que recuar" (Informante 1 ).

$\mathrm{Na}$ avaliação geral da coordenação, o movimento ficou limitado à discussão das Frentes, já que a execução da proposta demandava tempo e energia dos militantes. Afinal, havia uma responsabilidade com recursos públicos e com os inúmeros desempregados que o movimento havia mobilizado. As outras pautas ficaram forçosamente proteladas diante da demora na resolução das Frentes de Trabalho.

Somando-se a quantidade de tarefas exigidas, havia, ainda, preocupação com a forma de implantação das Frentes, que deveria ser coerente com a proposta militante do movimento; caso contrário, a proposta poderia se tornar assistencialista.

Posteriormente, o movimento assumiu a luta por moradia como pauta prioritária, que o levou a realizar ocupações urbanas e resistir às remoções de comunidades pobres. Esses, até hoje, constituem os dois eixos predominantes da atuação do MCP.

Desde seu início, o MCP apoiou algumas ocupações de terrenos para moradia. Entretanto, essas ocupações não eram organizadas pelo movimento, mas ocorriam de forma autônoma e, posteriormente, eram agregadas ao MCP. Ainda em 2004, foi organizado um núcleo do movimento na chamada ocupação "Che Guevara", localizada na BR 116. Em junho de 2005, centenas de famílias ocuparam um terreno próximo ao Morro da Vitória, no bairro Vicente Pinzón, zona leste de Fortaleza. Nessa ocupação, os moradores sofreram com a violência de homens armados que efetuaram disparos, atingindo alguns ocupantes, causando uma morte. O Judiciário ordenou o despejo da 
ocupação, o qual, de acordo com a nota do movimento, foi executado por mais de 900 policiais. Vários daqueles despejados passaram a se organizar no MCP do Morro da Vitória. Em 2007, no bairro do Caça e Pesca, outra ocupação, denominada "Beira Rio", ocorreu com o apoio do MCP e, em seguida, passou a constituir um núcleo do movimento.

Entre 18 a 21 de abril de 2008, o MCP realizou o seu $1^{\circ}$ Encontro, onde foi afirmada a luta pela moradia como pauta prioritária do movimento para o período seguinte, seja pela organização de novas ocupações urbanas ou pela resistência aos despejos de famílias nas já existentes. Menos de um mês antes do encontro, o MCP participou de um ato nacional, que ocorreu em nove estados. Os objetivos do que foi intitulado "Jornada Nacional de Luta Urbana" eram: habitação digna, emprego, transporte público, educação pública de qualidade, creche para todas as crianças de 0 a 6 anos e "tarifa social" de energia elétrica, ou seja, redução do valor dessa taxa para a população pobre. Essas e outras reivindicações foram expressas no "Manifesto Popular de 28 de Março", que afirmava que o povo pobre do Brasil vivia indignamente em favelas, cortiços e áreas de risco. Por isso, se levantavam em um único gesto de resistência contra as condições de vida miserável que os afetavam.

O manifesto enfatizava que o modelo neoliberal sufocava a população pobre, pois o dinheiro que escoa para banqueiros e especuladores como pagamento de uma dívida "impagável" seria suficiente para solucionar as demandas de habitação, infraestrutura urbana e de serviços em todo o país. No "jogo de ilusões" das grandes políticas públicas, para o povo sobravam somente "migalhas".

Além disso, o texto assinala que nenhum governo no Brasil havia priorizado uma política de Reforma Urbana que levasse em consideração os interesses populares, e que Lula aprofundou esse caminho, inclusive porque os recursos do Programa de Aceleração do Crescimento $(\mathrm{PAC})^{9}$ teriam beneficiado, de fato, mais os empresários do setor imobiliário e da construção civil do que o povo carente de moradia. Ademais,

O Ministério das Cidades e seus "espaços de participação", apresentados como avanços na efetivação de uma política urbana democrática, não representaram nenhum grande passo na solução de nossos problemas. Ao contrário, reproduzem uma forma burocrática e elitista de se tratar as questões urbanas.

A ação do MCP nesse ato nacional se deu pela ocupação da Secretaria de Assistência Social de Fortaleza com 400 manifestantes, além de um protesto em frente

\footnotetext{
${ }^{9}$ Pacote de investimentos estruturais lançado no início do segundo mandato de Lula.

Em Debat: Rev. Dig., ISSNe 1980-3532, Florianópolis, n. 6, p. 129-152, jul-dez, 2011.
} 
ao Palácio Iracema, sede do governo estadual do Ceará. O movimento também ocupou as secretarias estaduais de Habitação e do Trabalho.

Em 03 de julho de 2009, setenta e cinco famílias ocuparam um terreno baldio na Praia do Futuro. De acordo com a nota da ocupação denominada "Raízes da Praia", o espaço, pertencente à família Otoch, estava abandonado há mais de vinte cinco anos, portanto, "não cumpria função social e sobre o qual ninguém exercia posse" (NOTA..., 2009). Grande parte das famílias que ocupavam o terreno havia participado da ocupação no morro da Vitória, de onde foram despejadas.

A nota da ocupação afirma que os programas habitacionais, no geral, consistem em distribuir recursos para as construtoras construírem conjuntos habitacionais de péssima qualidade em terras consideradas de baixo valor. $\mathrm{O}$ texto prossegue fazendo uma dura crítica ao programa "Minha casa, minha vida", aplicado pelo Governo Lula, que, segundo o documento, não diferia dos programas dos governos anteriores, pois:

ilude o povo ao insinuar que as pessoas realizarão seu sonho, enquanto na verdade menos de 15.000 (se a meta for cumprida) das mais de 150.000 famílias fortalezenses que compõem o triste déficit habitacional serão beneficiadas. Por isso, entendemos que para conquistar nossa terra e construir nossas casas não adianta esperar pelo governo, devemos partir para luta. (NOTA..., 2009).

Meses depois, em abril de 2010, o MCP, em conjunto com o MST, realizou a ocupação de um terreno no bairro do José Valter. Cerca de quinhentas famílias foram cadastradas na ocupação "Comuna da Terra 17 de abril". O movimento permaneceu em negociação com os governos municipal e estadual, que propuseram a retirada das famílias do terreno, que pertence a um comerciante da região, e o reassentamento destas em outro local. Os ocupantes rejeitaram a proposta e lá permanecem até a data de conclusão deste artigo.

Atualmente uma das principais ações desenvolvidas pelo $\mathrm{MCP}$ na luta por moradia é a articulação do Comitê Popular da Copa de 2014, que visa agregar as populações atingidas pelas remoções em decorrência das obras previstas para a preparação do evento. No manifesto intitulado: "Minha Casa é minha luta", assinado pela Brigada Antônio Conselheiro - núcleo do MCP da região do Parque Água Fria, afirma-se que, com as obras relacionadas à Copa do Mundo ${ }^{10}$, Fortaleza sofrerá com o aumento da "especulação imobiliária, destruição do meio ambiente, das comunidades, das praias, dos rios, da mobilidade urbana e também das pessoas, principalmente as

\footnotetext{
${ }^{10}$ Ampliação de várias avenidas, construção de viadutos, edificação de grandes equipamentos turísticos (Acquario Ceará, novo Centro de Eventos do Ceará), e a reforma do estádio Castelão.

Em Debat: Rev. Dig., ISSNe 1980-3532, Florianópolis, n. 6, p. 129-152, jul-dez, 2011.
} 
pobres, removidas de sua morada e local de convivência, onde construíram sua cultura"; e que a Copa apenas legitimará a realização de obras há tempos planejadas por governos e empresários, representando "o avanço e aprofundamento de um modelo de desenvolvimento iniciado com 'o governo das mudanças' dos novos empresários (Tasso e Cia.), e que continua plenamente na gestão Cid Gomes e Luizianne Lins”.

$\mathrm{O}$ documento ressalta ainda que, conjugado às remoções, ocorre um processo de estigmatização e criminalização da população pobre residente em bairros periféricos pela "ocupação militar" dessas áreas por policiais ou por grupos armados particulares, “o que resulta em justificação da expulsão de suas terras pela especulação imobiliária e pelo Estado, sob a desculpa de combate ao tráfico ou até mesmo da 'regularização' fundiária."

Assim, o manifesto conclama a resistência dos que foram ou serão ${ }^{11}$ afetados pelas remoções, e de outros setores que queiram lutar contra a especulação imobiliária e os governos "bancados por empresários" que promovem essas remoções. E, assim, evitar a completa apropriação da cidade pelo capital. (MOVIMENTO..., 2009).

\section{Considerações finais}

A experiência do MCP em meio aos desvios e disjunções que marcaram sua relação com a Administração Luizianne Lins é emblemática por demonstrar a manifestação de sujeitos antagônicos diante das contradições econômicas materializadas na dinâmica da expansão urbana e o processo de "transformismo" nas relações sociais travadas pelo poder dominante a esses sujeitos antagônicos.

Conforme um dos entrevistados, o MCP foi um "grito da conjuntura" marcada pela emergência de grande mobilização popular, mesmo que capitaneada pelo processo eleitoral e manifestando contradições até então latentes. O movimento foi capaz de atrair significativo contingente de maiorias sociais para exercer participação direta na política. Atuou, ainda, em relação à posterior tentativa de passivização desse "potencial ético-político" pela gestão municipal, situação que representou o deslocamento de

\footnotetext{
${ }^{11}$ No período de redação do manifesto, duas comunidades de Fortaleza foram removidas: "Lagoa da Zeza" e "Vila Cazumba", localizadas no bairro Luciano Cavalcante. As famílias foram transferidas para o Conjunto Maria Tomásia, no bairro Jangurussu, região limítrofe de Fortaleza com o município de Itaitinga. A construção desse conjunto habitacional foi fruto de uma deliberação do Orçamento Participativo (PREFEITURA..., 2008), contudo, os votantes da proposta aprovada na assembleia do OP não imaginavam que seria construído a mais de $10 \mathrm{~km}$ do antigo local de moradia.
}

Em Debat: Rev. Dig., ISSNe 1980-3532, Florianópolis, n. 6, p. 129-152, jul-dez, 2011. 
setores da força social dos subalternos para o campo da governabilidade e da reprodução do poder instituído.

A adesão destes setores ao novo consenso fabricado em plano nacional e local foi afiançada, em grande medida, com a possibilidade de ascensão social e material de militantes e dirigentes do próprio MCP, conforme assinalou um dos informantes: "antes ele (ex-dirigente do MCP) andava de ônibus e bebia no Bar do Pedrinho ${ }^{12}$, hoje em dia tem carro e almoça nos restaurantes da [Avenida] Beira-Mar com vereadores, empresários" (Informante 1).

Bourdieu (2007, p. 159) afirmou que o "aburguesamento" de lideranças operárias é uma forma particular de luta de classes: "aquela que os membros das classes dominadas deixam-se impor quando aceitam os desafios que lhe são propostos pelos dominantes". Ademais, a maioria dos integrantes de base do MCP pertencia a camadas sociais que, com exceções, não podem facilmente titubear ante a possibilidade de um emprego estável e acima da remuneração que provavelmente encontraria no mercado de trabalho.

Não se trata de analisar que a "cooptação" foi o elemento mais importante do processo. Em linhas gerais, foram apresentados elementos que interagem no processo da política, moderando posições, forçando uma revisão "prática" de determinados fundamentos programáticos e levando à adesão a preceitos morais e intelectuais do campo dominante.

Cumpre destacar, ainda, que após a saída de muitos militantes mais experientes, emergiu uma camada de jovens militantes, oriundos em sua maioria do movimento estudantil, que passaram a coordenar o MCP. Atraindo outros militantes do movimento estudantil para o popular. Pode-se afirmar que a distinção de faixa de renda e de perfil social entre novos e antigos militantes interferiu no sentido de manter o MCP com vida orgânica e autonomia política.

Pelo exposto, vale observar que, em tempos de crise, a classe dominante pode emprestar seu Estado para setores subalternos tomarem conta por algum período, desde que o devolvam mantendo intacta a substância da ordem de classe que o fundamenta. Finalmente, quais seriam as outras possibilidades de intervenção de um sujeito social coletivo nos processos institucionais sem que ele seja absorvido? Existiriam cavidades que permitiriam o ingresso na máquina estatal sem o risco de se aprisionar às suas

\footnotetext{
${ }^{12}$ Estabelecimento frequentado por petistas, próximo à sede estadual da agremiação, no bairro Benfica. Em Debat: Rev. Dig., ISSNe 1980-3532, Florianópolis, n. 6, p. 129-152, jul-dez, 2011.
} 
engrenagens? Observa-se que a institucionalização termina por ser algo forçoso para movimentos que vislumbrem uma ação mais articulada e certa permanência na história. Caso contrário, ficariam sujeitos a deixar de existir ou tornarem-se alheios à realidade.

\section{Referências Bibliográficas}

AZEVEDO, R. D. Os Conselhos Populares e a administração petista - Uma varinha de condão? Teoria e Debate, n. 4, set. 1988. Disponível em:

$<$ http://www.fpabramo.org.br/o-que-fazemos/editora/teoria-e-debate/edicoesanteriores/opiniao-os-conselhos-populares-e-administra>. Acesso em: 3 ago. 2010.

BOITO, A. As relações de classe na nova fase do neoliberalismo no Brasil. In:

CAETANO, G.; MAYA, M. L. Sujetos sociales y nuevas formas de protesta en la historia reciente de América Latina. Buenos Aires: CLACSO Libros, 2006, p. 271-296.

BOURDIEU, P. A distinção: crítica social do julgamento. São Paulo: Edusp; Porto Alegre: Zouk, 2007.

BRAGA, R. Risorgimento, fascismo e americanismo: a dialética da passivização. In: DIAS, E. F.; COGGIOLA, O. O outro Gramsci. São Paulo: Xamã, 1996, p. 167-182.

COUTINHO, C. N. A dualidade de poderes: Estado, revolução e democracia na teoria marxista. 2. ed. São Paulo: Brasiliense, 1987.

- A época neoliberal, Outubro 2007. Disponível em:

http://www.acessa.com/gramsci/?page=visualizar\&id=790. Acesso em: 8 dez. 2008.

DAGNINO, E. ¿Sociedade civil, participação e cidadania: de que estamos falando? In: Daniel Mato (Coord.), Políticas de ciudadanía y sociedad civil en tiempos de globalización. Caracas: FACES, Universidad Central de Venezuela, 2004. p. 95-110.

DANIEL, C. Sociedade: Participação popular. Teoria e Debate, n. 2. Fundação Perseu Abramo, mar. 1988. Disponível em: $<$ http://www.fpabramo.org.br/o-quefazemos/editora/teoria-e-debate/edicoes-anteriores/sociedade-participacao-popular $>$. Acesso em: 3 ago. 2010.

DEMIER, F. As transformações do PT e os rumos da esquerda no Brasil. Rio de Janeiro: Bom Texto, 2003. 
DIAS, E. F; COGGIOLA, O. L. A. O outro Gramsci, São Paulo: Xamã, 1996.

FILGUEIRAS, L.; GONÇALVES, R. A economia política do governo Lula. Rio de Janeiro: Contraponto, 2007.

FRANK, André G.; FUENTES, M. Dez Teses Acerca dos Movimentos Sociais. In: Lua Nova 17, 1989, p.19.

GOHN, M. G. M. História dos Movimentos e Lutas Sociais. 3. ed. São Paulo: Loyola, 2003 .

. Teoria dos Movimentos Sociais. 4. ed. São Paulo: Loyola, 2004.

GONDIM, L. M. P. Os movimentos sociais urbanos: organização e democracia interna. In: Revista Sociedade e Estado. Universidade de Brasília. Vol. VI (2) - jul./dez. Brasília: Ed. UNB, 1991.

GRAMSCI, A. Cadernos do Cárcere, v. 3. Maquiavel, notas sobre o Estado e a política. 3. ed. Rio de janeiro: Civilização Brasileira, 2002.

Cadernos do Cárcere, v. 5. O Risorgimento. Notas sobre a história da Itália. 3. ed. Rio de janeiro: Civilização Brasileira, 2002.

HOLLOWAY, Jonh. Mudar o mundo sem tomar o poder. São Paulo: Boitempo, 2003.

HOUTART, F. Os movimentos sociais e a construção de um novo sujeito histórico. In: BORON, A. A.; et al. A teoria marxista hoje. São Paulo: Expressão Popular, 2006, p. 421-430.

IASI, M. L. As metamorfoses da consciência de classe: o PT entre a negação e o consentimento. São Paulo: Expressão Popular, 2006.

INFORMANTE 1. 5/06/2009. Depoimento. In: COSTA JUNIOR, Pedro Wilson Oliveira da. O ESTREITO FIO DA NAVALHA: Participação e Transformismo na relação do Movimento dos Conselhos Populares (MCP) com a gestão de Luizianne Lins em Fortaleza (2005 a 2009). Dissertação de Mestrado, Universidade Federal do Ceará, Programa de Pós-Graduação em Sociologia, 2010. [Entrevista concedida ao autor] 
INFORMANTE 2. 6/06/2009. Depoimento. In: COSTA JUNIOR, Pedro Wilson Oliveira da. 2010. [Entrevista concedida ao autor]

INFORMANTE 3. 14/12/2009. Depoimento. In: COSTA JUNIOR, Pedro Wilson Oliveira da. 2010. [Entrevista concedida ao autor]

INFORMANTE 4. 15/12/2009. Depoimento. In: COSTA JUNIOR, Pedro Wilson Oliveira da. 2010. [Entrevista concedida ao autor]

INFORMATIVO do IMOPEC. Conselhos Populares, uma formação politica permanente. In: Raizes, Ano 14, n. 49, jan./mar. 2005.

MARX, Karl. O Capital. Capítulo VI. 2. ed. São Paulo: Centauro, 2004.

MIRZA, C. A. Movimientos sociales y sistemas políticos en América Latina. Buenos Aires: CLACSO, 2006.

MOURIAUX, R.; BEROUD, S. Para uma definição do conceito de movimento social. In: LEHER, R.; SETÚBAL, M. (Org). Pensamento crítico e Movimentos Sociais: diálogos para uma nova práxis. São Paulo: Cortez, 2005.

MOVIMENTO DOS CONSELHOS POPULARES. Proposta metodológica para lutarmos por Frentes de Trabalho. Documento impresso, s/d. . Minha casa, é minha luta. dez 2009. (Documento impresso). (Cartilha).

Trabalho e poder para o povo de Fortaleza. Expressão Gráfica. Fortaleza, s/d. . Princípios. Fortaleza: Expressão Gráfica, Dez. 2004.

NOTA da Ocupação Raízes da Praia. Panfleto impresso. Jul. 2009.

OLIVEIRA, F. Crítica à razão dualista; O ornitorrinco. São Paulo: Boitempo, 2003. 
Disponível em: http://www.cebrap.org.br/imagens/Arquivos/o_momento lenin.pdf

PONTUAL, P.; ALMEIDA SILVA, C. C. R.; Participação popular nos governos petistas: trajetórias, mecanismos e caráter. In: MAGALHÃES, I.; BARRETO, L.; TREVAS, V. (Org). Governo e Cidadania: Balanço e reflexões sobre o modo petista de governar. São Paulo: Ed. Fundação Perseu Abramo, 1996.

PREFEITURA DE FORTALEZA. Histórias da participação: Lagoa da Zeza. 04/09/2008. Disponível em:

http://www.fortaleza.ce.gov.br/op/index.php?option=com_content\&task $=$ view\&id $=24$

PROGRAMA DE GOVERNO. Por amor a Fortaleza: construir uma cidade bela, justa e democrática. Coordenadoria de Comunicação Social da Prefeitura. Fortaleza:

Expressão Gráfica, 2006 [2004].

REY, M. T. La autonomía como búsqueda, El Estado como contradicción. Buenos Aires: Prometeo Libros, 2004.

SANTOS, B. S. Os novos movimentos sociais. In: LEHER, R.; SETÚBAL, M., (Orgs). O Pensamento Crítico e Movimentos Sociais: Diálogos Para Uma Nova Práxis. São Paulo: Cortez, 2005.

SECRETARIA DE DESENVOLVIMENTO ECONÔMICO DO MUNICÍPIO DE FORTALEZA. Programa de Frentes Urbanas de Trabalho. Fortaleza: 2006

(Documento impresso). 